\title{
Simulation of the combined process "helical rolling-pressing" in the software package Simufact. Forming
}

\author{
Naizabekov Abdrakhman, Lezhnev Sergey*, Panin Evgeniy, Arbuz Alexandr \\ Rudny industrial institute, Rudny, Republic of Kazakhstan
}

\begin{abstract}
This work is devoted to the simulation of new energy-saving combined process "helical rolling-pressing" in program Simufact Forming. During the simulation were studied the main parameters of stress-strain state and microstructure. The variation of the main technological parameters showed that the influence of the heating temperature of the workpiece plays a significant role in the degree of grain grinding. While the speed of deformation, allowed by the mill design limits, has no significant effect on the microstructure.
\end{abstract}

\section{Introduction}

The combination of helical rolling and subsequent pressing in equal-channel angular matrix allows to implement the scheme of stress-strain state with the intense shift of metal layers at helical rolling in the first deformation zone and the unification of intense shear deformation angular pressing with torsion in the second deformation zone (Fig. 1).

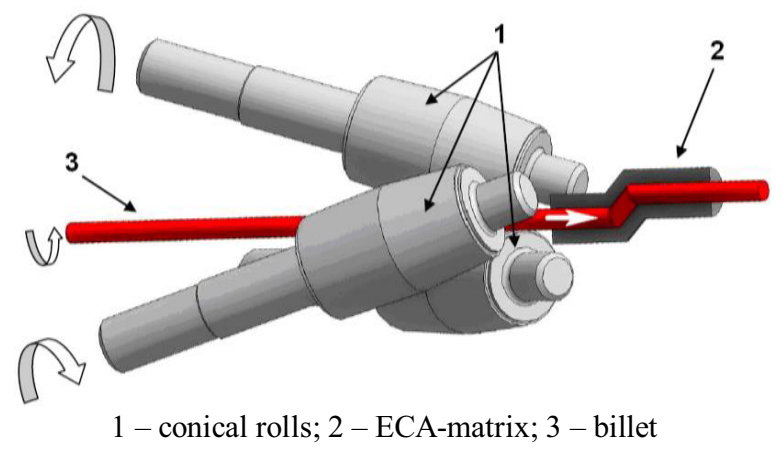

Figure 1. Combined process "helical rolling-pressing"

Thus non-deformed central part of the workpiece in the first deformation zone will receive intensive deformation in another diagram in the second zone - in ECA-matrix. In addition, it is interested to study the parameters of angular pressing with torsion. In fact, this is the process of continuous extrusion with the elements of the torsion of the workpiece inside the matrix. It will increase the level of accumulated plastic deformation in the volume of the workpiece and contribute to the elaboration of the central zone. This creates good conditions for the formation of ultrafine-grained structure throughout the volume of a round workpiece.

In the study of any process forming a key position ahead of laboratory or industrial tests is to study the stress-strain state (SSS). This will allow to identify the distribution of stresses and strains in the present process, and also to determine their critical values, which, in turn, will allow you to check the working tool for strength.

To determine the values of stress and strain need to find the values of the components of the corresponding tensors, for which a three-dimensional flow of metal is very difficult to visualize. So usually when considering the parameters of the SSS use simple indicators of the intensity of strain and stress, or so-called equivalent strain and equivalent stress, which include components of deformations and stresses in the following form:

$$
\begin{aligned}
& \varepsilon_{E Q}=\frac{\sqrt{2}}{3} \sqrt{\left(\varepsilon_{1}-\varepsilon_{2}\right)^{2}+\left(\varepsilon_{2}-\varepsilon_{3}\right)^{2}+\left(\varepsilon_{3}-\varepsilon_{1}\right)^{2}}, \\
& \sigma_{E Q}=\frac{1}{\sqrt{2}} \sqrt{\left(\sigma_{1}-\sigma_{2}\right)^{2}+\left(\sigma_{2}-\sigma_{3}\right)^{2}+\left(\sigma_{3}-\sigma_{1}\right)^{2}},
\end{aligned}
$$

where $\varepsilon_{1}, \varepsilon_{2}, \varepsilon_{3}$ - main strains,

$$
\sigma_{1}, \sigma_{2}, \sigma_{3} \text { - main stresses. }
$$

Also in the study of SSS is very useful is the study of the temperature conditions of the process, since the temperature change of deformable metal significantly affects the energy-power parameters of deformation.

\section{Initial model and temperature distribution}

In result of computer simulation of the combined process "helical rolling - pressing" in the software package Simufact.Forming was obtained a successful model of this process with the following optimum values:

- coefficient of friction in the rolls $-0,8$;

- coefficient of friction in the matrix - 0,1 ;

\footnotetext{
*Corresponding author: sergey_legnev@mail.ru
} 


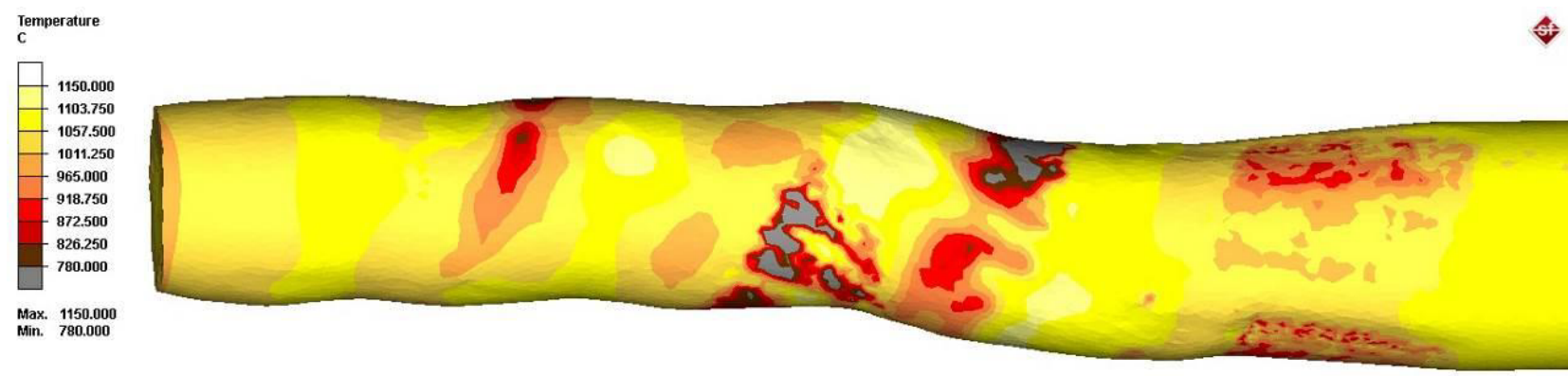

Figure 2. Temperature distribution $150^{\circ}$;

- the angle of intersection of channels in the matrix -

- the distance between matrix and deformation zone of the rolls $-15 \mathrm{~mm}$.

The initial workpiece was a rod with a diameter of 25 $\mathrm{mm}$ and a length of $150 \mathrm{~mm}$. Steel 15 was selected as material. Roll dimensions and their structural location consistent with the design of the laboratory rolling mill 10-30. The roll rotation speed was $100 \mathrm{rpm}$. Equal channel step matrix had channel diameter of $21 \mathrm{~mm}$. Temperature of the billet was accepted by $1000^{\circ} \mathrm{C}$, all tools in the model had a temperature of $20^{\circ} \mathrm{C}$.

In figure $2 \mathrm{a}, \mathrm{b}$ showed the temperature distribution of the workpiece. In the contact zone of the workpiece with the rolls the temperature is reduced to $950-970^{\circ} \mathrm{C}$. In the zone of junction of the channels of the matrix temperature is lowered to $850^{\circ} \mathrm{C}$. In further temperature drop across the section is leveled due to heat transfer from the central layer to surface.

\section{Stress state}

When considering the equivalent stress it should understand that this option does not show, what stress operates at a specific point - tensile or compressive. As a radical expression, its value is always positive. It shows the intensity of the action of the stress, i.e., is there at this point stress or not. Its value characterizes the average value of all stresses acting at a given point.

At the first stage, during helical rolling (figure 3 a) stress covers the entire deformation zone of the rolls. In zones of contact of metal with rolls its value reaches 150 $\mathrm{MPa}$, in zones free of contact, the value of this parameter reaches $120 \mathrm{MPa}$.

In the second stage, during pressing (figure $3 \mathrm{~b}$ ) stress covers a vast area, connecting two of the deformation. In longitudinal rolling with the support of such a merger does not occur, because there is no twisting of the blank, causing the growth of shear stresses. Due to the action of backpressure, stress within the deformation zone of the rolls is increased to $190 \mathrm{MPa}$ in the contact zones of the metal with the rolls. Free from contact zones, the value of this parameter is in the limit of $140 \mathrm{MPa}$. In the zone of junction of the channels of the matrix the magnitude of equivalent stresses up to $160 \mathrm{MPa}$.

There is also clearly tracks the forces of backpressure. Behind the zones of contact of metal with rolls arise extent of physical deformation area that is a consequence of two concurrent factors - backpressure from the side of the matrix and twisting of the workpiece.

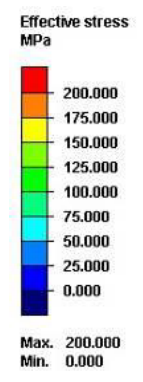

${ }_{\mathrm{MPa}}^{\mathrm{Ere}}$

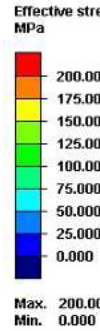

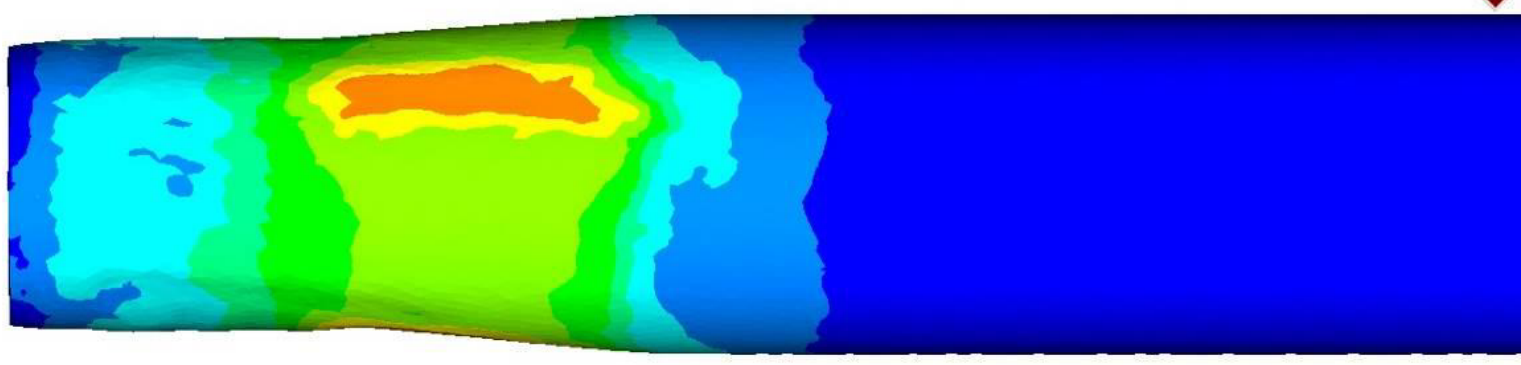

a)

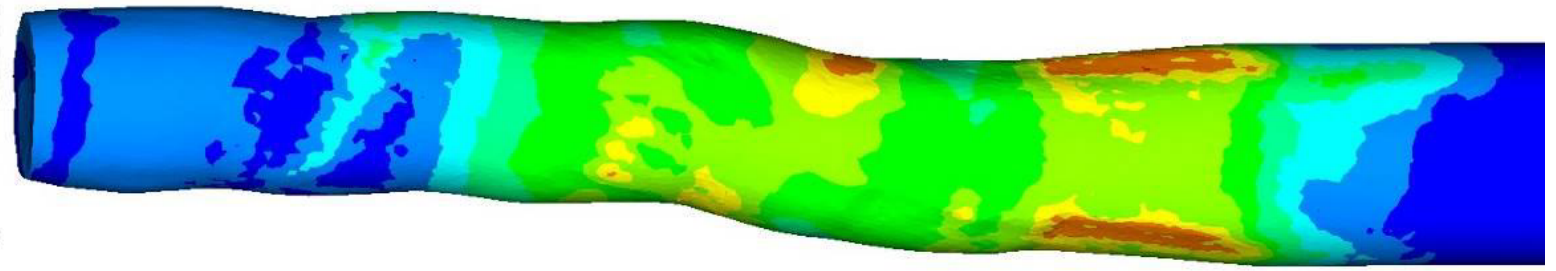

b)

Figure 3. Equivalent stress 


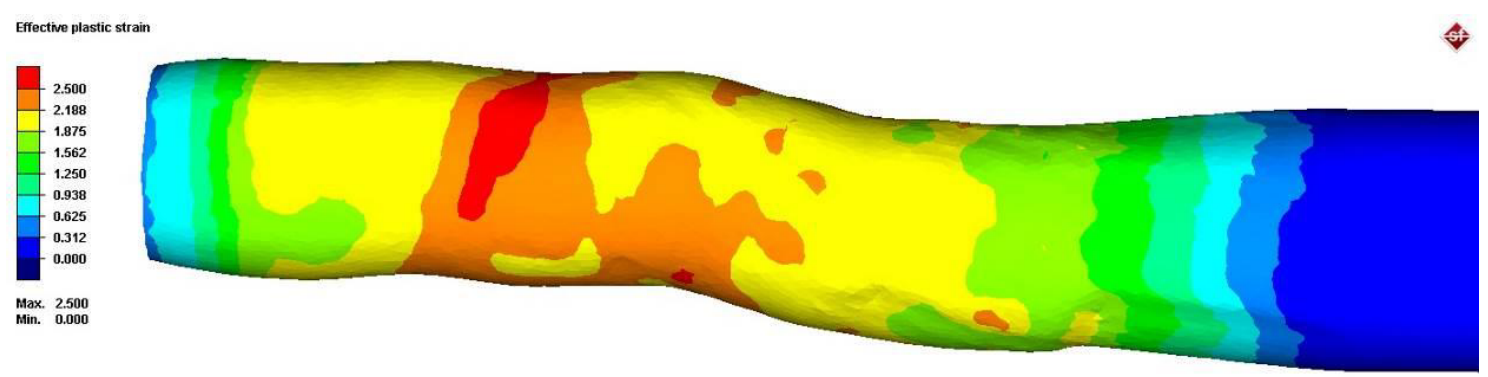

a)

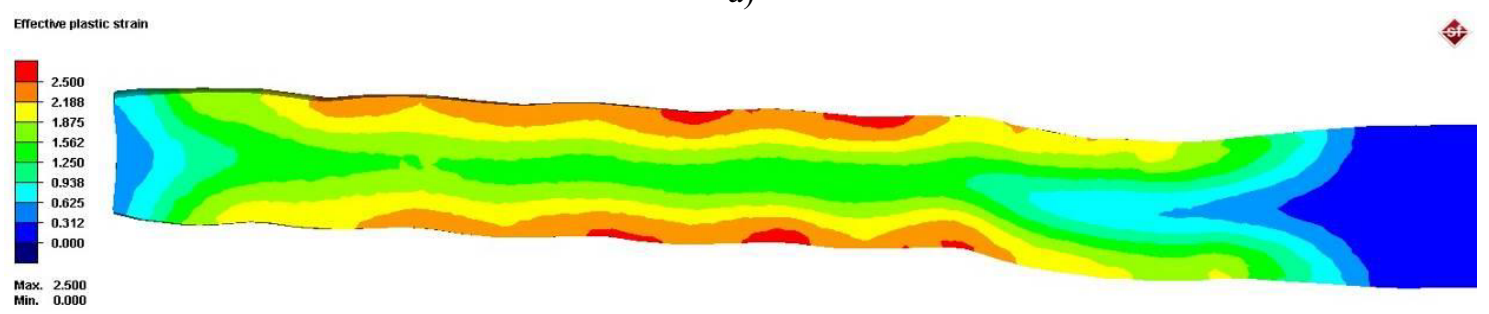

b)

Figure 4. Equivalent strain

\section{Strain state}

As noted above, to study the strain state use the indicator of intensity of deformation - equivalent strain, which includes major components of deformation. This option allows to monitor the degree of accumulated strain, which is cumulative.

When studying the strain state is necessary not only to ensure a high level of equivalent strain, required for the formation of subalternity patterns, but a uniform distribution of this parameter over the cross section of the workpiece.

During helical rolling (figure 4) deformation develops in the deformation zone of the rolls in the following form: its value reaches 1.2 in the surface layers; in central layers this parameter value is at 0.7 (figure $4 \mathrm{~b}$ ), i.e. the difference of the values of the equivalent strain reaches $72 \%$.

During pressing there is a significant increase of this parameter due to the implementation of shear deformation during the movement of billet through the channels of the matrix. The value of equivalent strain is 2.3 in the surface layers, in central layers the value of this parameter is at the level of 1.4 , i.e. the difference of the values of the equivalent strain reaches $64 \%$. Thus, the difference of values of this parameter after passing through the channels of the matrix decreased by $8 \%$.

Comparison of the values of equivalent strain in the surface and central layers of the billet showed that the distribution of this parameter over the cross section is rather uneven. It is therefore important to achieve a more uniform distribution of the equivalent strain over the cross section of the rod.

It can be concluded that the difference in equivalent strain in the central zone to the entrance to the matrix and after the matrix, equal to 0.7 , the difference is the portion of deformation corresponding to simple shear in the matrix. That is, the center of the workpiece when passing the channel matrix gains equivalent strain of 0.7 in the direction perpendicular to the direction of deformation of the previous stage and also perpendicular to the orientation of the structure of the central part. Several cycles of such deformation should contribute to the transformation oriented streaky structures in a more equiaxed, thus reducing the anisotropy of properties on the section of the rod.

\section{Modelling of microstructure evolution}

To study the evolution of microstructure was used the specialized database of the microstructure of the Matilda program, which uses the data of stress-strain state, strain rate and temperature of ready designed models to SIMUFACT.forming, complements them with the data of physic-chemical properties and their behavior for a given material and its structure from the database, then using the algorithm Yada [1], calculates the process parameters of static and dynamic recrystallization that may cause changes in grain size. Grain size is also calculated for each node of the finite element model and displayed at the end of the simulation at any convenient time for rendering the form.

During deformation there are two kinds of recrystallisation (static and dynamic), which have influence on initial grain size. Calculation of dynamic recrystallisation is the part of model, which refers to the processes in the forming zone. It starts when the effective $\log$. strain $\varepsilon$ exceeds the critical strain $\varepsilon_{\mathrm{k}}$. Main data in this model is Zener-Hollomon parameter:

$$
Z=\dot{\varepsilon} \exp \left(\frac{Q}{R T}\right)
$$

where $\dot{\varepsilon}$ - strain rate, $\mathrm{s}^{-1}$;

$Q$ - activation energy for forming, $\mathrm{J} / \mathrm{mol}$;

$R$ - gas constant $=8,3144 \mathrm{~J} /(\mathrm{mol} * \mathrm{~K})$;

$T$ - forming temperature, $\mathrm{K}$.

Critical strain for beginning of dynamic recrystallisation:

$$
\varepsilon_{\mathrm{k}}=\left[\mathrm{a} 1 \cdot \mathrm{D}_{0}{ }^{\mathrm{a} 2} \cdot \mathrm{Z}^{\mathrm{a} 3}+\mathrm{a} 4\right] \cdot \mathrm{a} 5
$$


where: a $\div$ a5 - model coefficients; $\mathrm{D}_{0}$ - initial gain size, $\mu \mathrm{m} ; \mathrm{Z}$ - Zener-Hollomon parameter.

Log. strain to $50 \%$ of dyn. recrystallisation:

$$
\varepsilon_{50}=\left[\mathrm{c} 1 \cdot \mathrm{D} 0^{\mathrm{c} 2} \cdot \exp (\mathrm{c} 3 / \mathrm{T}) \cdot \dot{\varepsilon}^{\mathrm{c} 4}\right]+\mathrm{c} 5
$$

where: $\mathrm{c} 1 \div \mathrm{c} 5$ - model coefficients.

Dynamic recrystallised part:

$$
\mathrm{X}_{\text {Dyn }}=1-\exp \left[\mathrm{fl} \cdot\left(\left(\varepsilon-\varepsilon_{\mathrm{k}}\right) / \varepsilon_{50}\right)^{\mathrm{f} 2}\right)
$$

where: $\mathrm{f} 1, \mathrm{f} 2$ - model coefficients.

Dynamic recrystallised grain size, $\mu \mathrm{m}$;

$$
\mathrm{D}_{\text {Dyn }}=\mathrm{d} 1 \cdot \mathrm{Z}^{\mathrm{d} 2}
$$

where: $\mathrm{d} 1, \mathrm{~d} 2$ - model coefficients.

Calculation of static recrystallisation is the part of model, when the workpiece segment leave the forming zone.This is valid until the recrystallisation process is interrupted to a new forming or a phase transition. It starts when the effective $\log$. strain $\varepsilon$ exceeds the critical strain $\varepsilon_{\mathrm{k}}$ and it ends when the temperature is below the lower application range boundary.

Mean log. strain after starting of dynamic recrystallisation:

$$
\varepsilon_{\mathrm{m}}=\mathrm{p} 2 \cdot\left(\varepsilon_{\mathrm{k}}+\varepsilon_{50} \cdot\left\{1-\exp \left[-\left(\varepsilon-\varepsilon_{\mathrm{k}}\right) / \varepsilon_{50}\right]\right\}\right)
$$

where: p2 - coefficent for model adaptation.

Time to $50 \%$ of static recrystallisation, s:

$$
\mathrm{t}_{50}=g 1 \cdot \varepsilon^{g 2} \cdot D_{0}^{g 3} \cdot \exp \left(\frac{g 4}{T}\right) \cdot \dot{\varepsilon}^{g 5}
$$

where: $\mathrm{g} 1 \div \mathrm{g} 5$ - model coefficients.

Time for begin and end of static recrystallisation, s:

$$
\left\{\begin{array}{l}
\mathrm{t}_{05}=\mathrm{b}_{1} \times \mathrm{t}_{50} \\
\mathrm{t}_{95}=\mathrm{b}_{2} \times \mathrm{t}_{50}
\end{array}\right.
$$

where: b1, b2 - model coefficients.

Temperature corrected pause time, s:

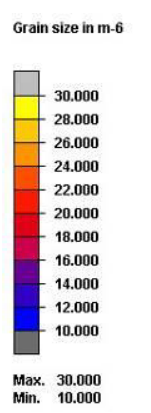

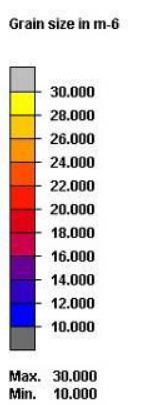$$
\mathrm{t}_{\mathrm{P}_{-} \text {kor }}=\sum\left\{d_{T i} \cdot \exp \left[-\left(\frac{Q_{S T}}{1000 \cdot R \cdot T}\right)\right]\right\}
$$

where: $d_{T i}$ - length of time increment $i, s$;

$\mathrm{Q}_{\mathrm{ST}}$ - activation energy for static recrystallisation, $\mathrm{J} / \mathrm{mol}$.

Static recrystallised part:

$$
\mathrm{X}_{\text {Stat }}=1-\exp \left[\mathrm{m} 2 \cdot\left(\mathrm{t}_{\mathrm{P}_{-} \mathrm{kor}} / \mathrm{t}_{50}\right)^{\mathrm{ml}}\right]
$$

where: $\mathrm{m} 1, \mathrm{~m} 2$ - model coefficients.

Static recrystallised grain size, $\mu \mathrm{m}$ :

$$
\mathrm{D}_{\text {Stat }}=\left[\mathrm{s} 1 \cdot \varepsilon^{\mathrm{s} 2} \cdot \mathrm{D}_{0}^{\mathrm{s} 3} \cdot \mathrm{Z}^{\mathrm{s} 4}\right]+\mathrm{s} 5
$$

where: s1 $\div$ s 5 - model coefficients.

Mean grain size at the end of recrystallisation:

$$
\begin{aligned}
D= & X_{D y n} D_{D y n}+\left(1-X_{D y n}\right) X_{S t a t} D_{S t a t} \\
& +\left[1-X_{D y n}-\left(1-X_{D y n}\right) X_{S t a t}\right] D_{0}
\end{aligned}
$$

In large forming pauses the process of grain growth starts directly after the end of dynamic and static recrystallisation When $\left(\mathrm{X}_{\text {Dyn }}+\mathrm{X}_{\text {Stat }}\right)>95 \%$ and $\left(\mathrm{t}_{\mathrm{P} \text { kor }}-\right.$ $\left.t_{95}\right)>0$ the new mean grain size $\mathrm{mKG}$ in $\mu \mathrm{m}$ is calculated according to:

$$
\mathrm{mKG}^{\mathrm{w} 1}-\mathrm{D}^{\mathrm{w} 1}=\mathrm{w} 2 \cdot\left(\mathrm{t}_{\mathrm{P} \_} \text {kor }-\mathrm{t}_{95}\right) \cdot \exp [-\mathrm{Q} /(\mathrm{RT})]
$$

where: w1, w2 - model coefficients.

Thus, in the initial model were imported property data of AISI1015 steel corresponding to steel 15. In the simulation of the microstructure in the program uses the assumption that the workpiece before the deformation has a uniform structure with the same grain size at any point. As the source size adopted, the average grain diameter of $30 \mu \mathrm{m}$, which corresponds to the $7^{\text {th }}$ score [2].

After calculation were obtained the results of the microstructure evolution, which were considered separately on the surface and in the longitudinal section of the billet. During helical rolling the surface layers of the workpiece are subjected to intense deformation, leading to considerable grain refinement from $30 \mu \mathrm{m}$ to $20 \mu \mathrm{m}$, which corresponds to the $8^{\text {th }}$ score (figure 5). After passing through the channels of the matrix through the implementation of shear deformation there is a further grinding of the grain to $14 \mu \mathrm{m}$, which corresponds to $9^{\text {th }}$ score.
Central layers of the billet during helical rolling are deformed less intensely - here the grain size varies from $30 \mu \mathrm{m}$ to $28 \mu \mathrm{m}$. The greatest interest represents an area of the workpiece after passing through the channels of the matrix. Here there is a grinding of grain along the entire cross section of the workpiece in the central zone, the grain size changes from $28 \mu \mathrm{m}$ to $22 \mu \mathrm{m}$. Thus, after one cycle of deformation is the difference of the values of the grain size is $57 \%$, which once again confirms the fact that the implementation of this combined process of elaboration of the workpiece in the cross section is uneven and levelling properties over the cross section it is necessary to conduct several cycles of deformation. It should also be noted that the simulation results of the 
microstructure quite well correlate with the results of a study of equivalent strain, the distribution of which in the cross section is largely similar to the picture of the microstructure evolution.

After study of basic model was given the task to identify how to affect the grain size change of the main technological parameters, namely, temperature, heating of the workpiece and the speed of deformation. These parameters were chosen from the considerations that they are the most flexible in terms of changing values. Temperature is easy enough to vary during the billet heating process in the furnace. The rate of deformation in this combined process is determined by the rolling speed on the mill screw, the value of which is also easy to change when the frequency converter.

\subsection{Microstructure evolution in models with varying values of heating temperature of the workpiece}

For studying the effect of temperature on the evolution of microstructure were built models with the heating temperatures of the workpiece $1150{ }^{\circ} \mathrm{C}$ and 850 ${ }^{\circ} \mathrm{C}$. As shown the study of these models, the effect of temperature on the change of grain size is very significant. Lowering the temperature causes the intensification of grinding of the original grain, while the increasing temperature, the process slows down. This is well illustrated by the histogram shown in figure 6 . This is because with increasing temperature of heating of metal in it significantly accelerates the process of static recrystallization, which is an undesirable character because it leads to the emergence and growth of new grains. At lower temperatures, this type of recrystallization is slowed down significantly, and the grain refinement is under the influence of dynamic recrystallization, which takes place directly in the deformation process.

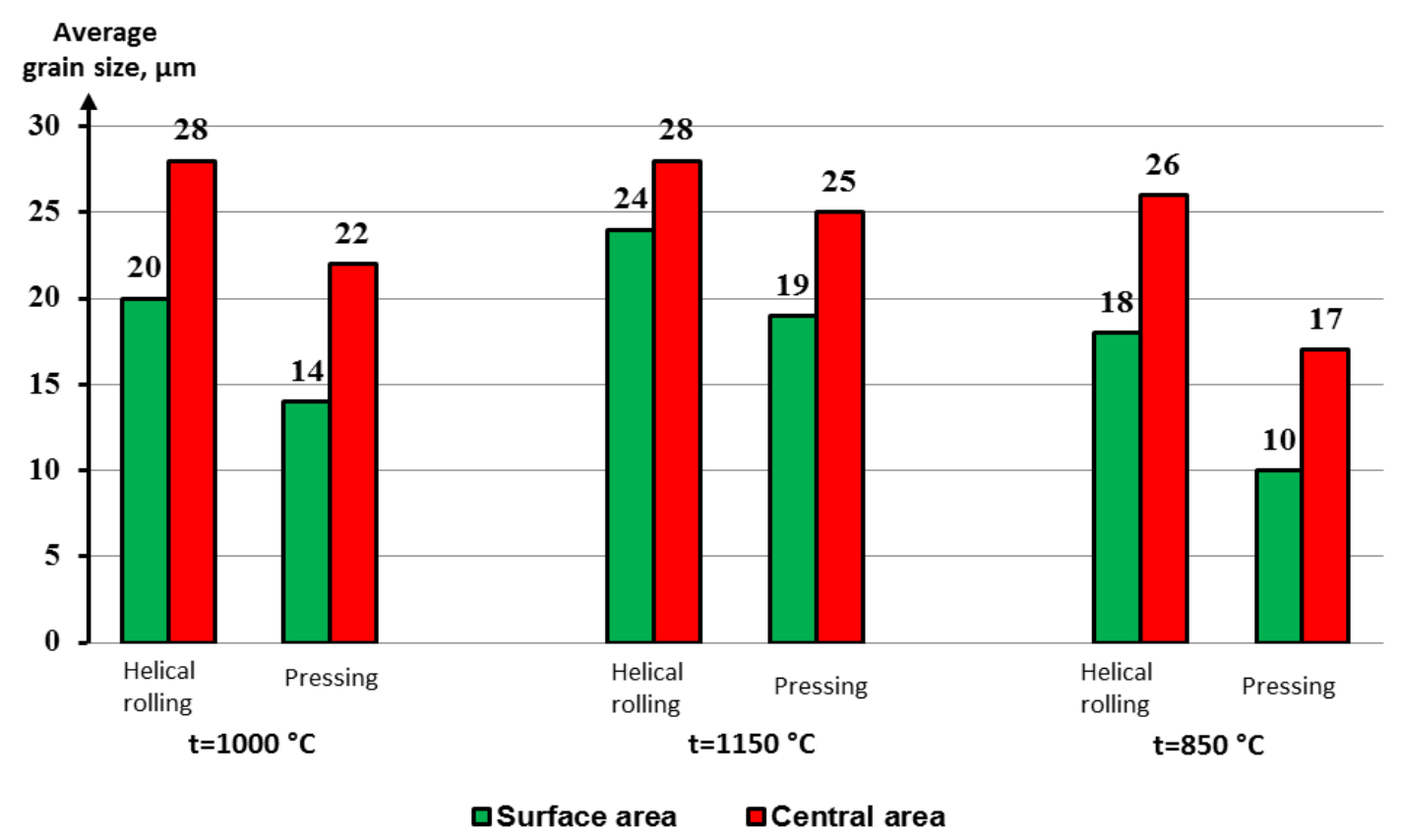

Figure 6. Change of grain size with variation of the heating temperature of the workpiece

In the analysis of the dispersion of values, it was found that in a model with a heating temperature of the workpiece $1150{ }^{\circ} \mathrm{C}$ during helical rolling the difference of grain size between the central and surface areas is $17 \%$; after pressing in the matrix, this difference is $32 \%$. The increased scatter is due to the fact that, despite the increased value of a heating temperature of the workpiece at its contact with the working tool surface layers cool more rapidly than central layers. Therefore, when deformation in the matrix, where contact with the tool has a greater length than helical rolling, there is an intensive grain refinement in the surface area.

In the model with a heating temperature of the workpiece $850{ }^{\circ} \mathrm{C}$, during helical rolling the difference of grain size between central and surface areas is $44 \%$; after pressing in the matrix, this difference reaches $70 \%$. It is necessary to note not only the increase of dispersion between central and surface areas, but also the decline in overall grain size compared to the base model. Both of these factors are a consequence of lowering the heating temperature of the workpiece, which leads to a decrease of static recrystallization.

It should be noted that despite the increased level of variance model with low temperature heating is optimal in terms of more intensive grinding grain. This is particularly evident when comparing values of grain size in central part, which worked out much worse surface area. As has been shown in studies of the deformed state, to align the values of accumulated strain needed to perform multiple passes of deformation. In this case, it will also reduce the variation in grain size. Therefore, for the subsequent multi-pass deformation it was decided to use a heating temperature of the workpiece equal to 850 ${ }^{\circ} \mathrm{C}$. 


\subsection{Microstructure evolution in models with variable speed of deformation}

To study the influence of speed of deformation on the microstructure evolution it was necessary to construct additional models with different rolling velocities and compare them with the base model, where the roll rotation speed is $100 \mathrm{rpm}$.

Because the helical rolling mill is equipped with system regulation of roll rotation speed using a frequency converter, it was decided to study the change in grain size under extreme values of rolling speed. In particular, the minimum technologically possible roll rotation speed is $10 \mathrm{rpm}$; the maximum possible roll speed is $300 \mathrm{rpm}$.
This choice was made due to the fact that in many works [3-7] in the study of ECAP has been proven that changing the speed of deformation in a relatively small range (3-5 times) had no effect on change of grain size.

The simulation results of the microstructure shown in figure 7, confirmed the results of the above studies. By varying the rate of deformation of from 10 to $300 \mathrm{rpm}$, the microstructure of the billet is almost constant. A small change in the mean diameter of the grains $(1-2 \mu \mathrm{m})$ occurs only in the surface area at low speed rolling. This is directly related to the fact that when reducing the speed of deformation of the workpiece has a more prolonged contact with the tool, resulting in stronger surface layers cool down.

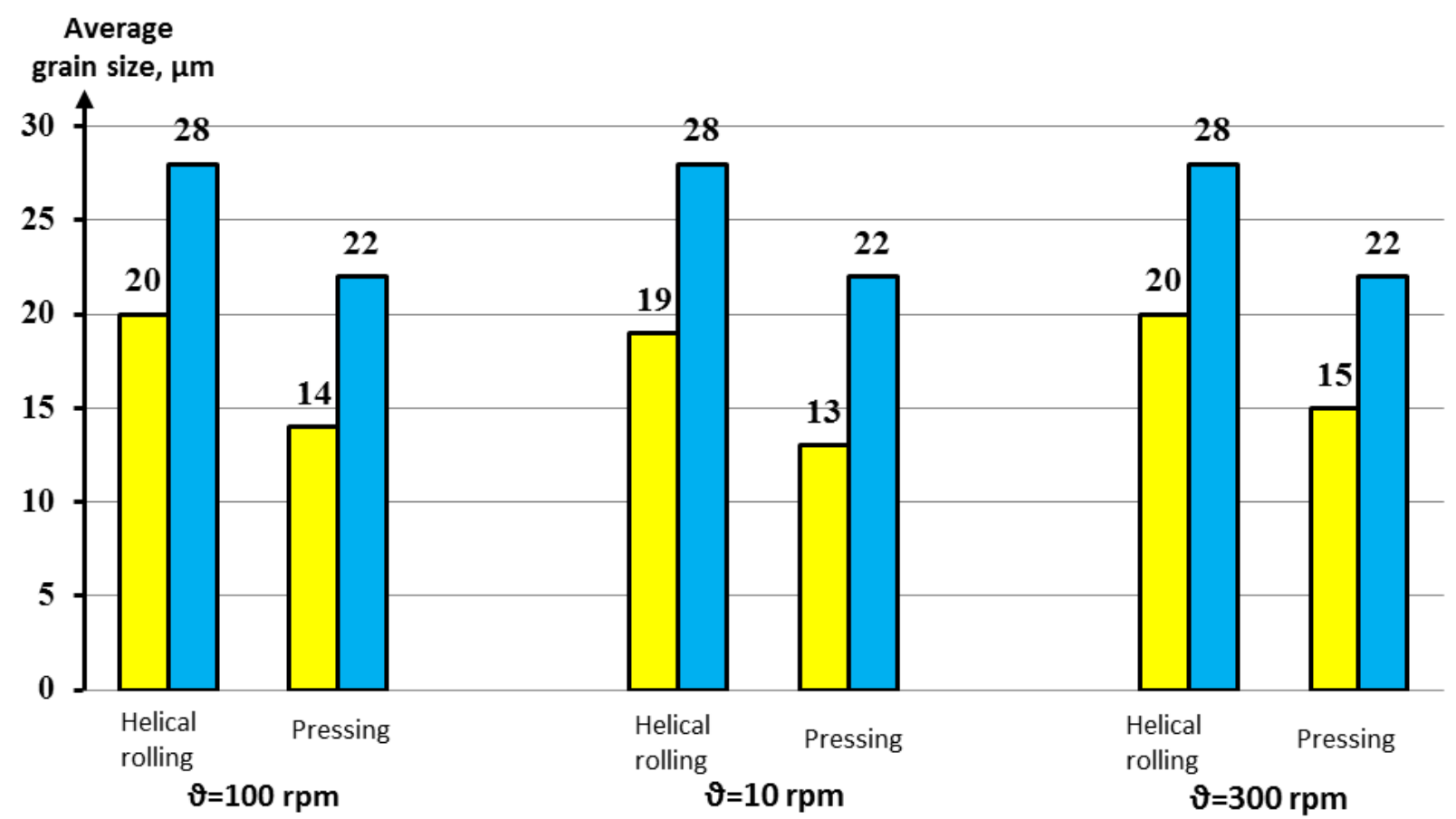

\section{口Surface area $\quad$ Central area}

Figure 7. Change of grain size with variation of speed of deformation

It should be noted here that the variation of speed of deformation will be impractical decision. Increasing the speed of rotation of the rolls leads to increased dynamic loads on the frame of a rolling mill, which is a negative factor. An excessive decrease in strain rate is also undesirable because it leads to a substantial cooling of the workpiece and possible growth of grain in central parts of large workpieces due to static recrystallization.

Despite the fact that in the study of the ECAP process, it was found that the decrease in the deformation temperature is a favorable condition for the formation of fine patterns, in the implementation of this combined process may also occur such situation when the workpiece has cooled so that the forces generated by the mill will not be enough to push the workpiece through the channels of the matrix. Therefore, for the subsequent multi-pass deformation it was decided to use the rate of deformation of the basic model, equal to $100 \mathrm{rpm}$.

\subsection{Microstructure evolution after several cycles of deformation}

Initial model for multipass deformation was the model with low heating temperature of the workpiece $-850^{\circ} \mathrm{C}$, which was identified as the most optimal. The deformation in the $2^{\text {nd }}$ and $3^{\text {rd }}$ passage was effected under the following conditions:

- second pass: the workpiece with diameter of $20 \mathrm{~mm}$ was rolled to a diameter of $17 \mathrm{~mm}$ and passed through a matrix with a channel diameter of $18 \mathrm{~mm}$;

- third pass: the workpiece with a diameter of $17 \mathrm{~mm}$ was rolled to a diameter of $14 \mathrm{~mm}$ and passed through a matrix with a channel diameter of $15 \mathrm{~mm}$.

As a result the following data were obtained (Fig. 8). In the first pass after the helical rolling the difference in average grain diameter between central and surface area 
was $8 \mu \mathrm{m}$; after pressing in the matrix this difference reached $7 \mu \mathrm{m}$.

During the second pass the grinding of grain during helical rolling is not as intense as in the first pass. This is because the compression in this passage was $3 \mathrm{~mm}$, which is less than in the first passage $(5 \mathrm{~mm})$. Here, the average grain size in the surface area was $8 \mu \mathrm{m}$, in the central zone was $13 \mu \mathrm{m}$, i.e. the difference was $5 \mu \mathrm{m}$. During subsequent pressing in the matrix, the average diameter of the grain was reduced to 6 microns in surface area and $10 \mu \mathrm{m}$ in the central zone. In this case, the difference value is decreased to $4 \mu \mathrm{m}$.
During the third pass after the helical rolling average diameter of the grain in the surface area was $5 \mu \mathrm{m}$, in the central zone was $9 \mu \mathrm{m}$, i.e., the difference amounted to 4 microns. When pressing in the matrix average grain size decreased to $3 \mu \mathrm{m}$ in the surface area and $6 \mu \mathrm{m}$ in the central zone, i.e. the difference of the values was only 3 $\mu \mathrm{m}$.

Thus, after study of model of multi-pass deformation it was found that with increase in the number of passes there is not only a general decrease of average diameter of the grain, and the gradual equalization of this parameter between the central and surface area.

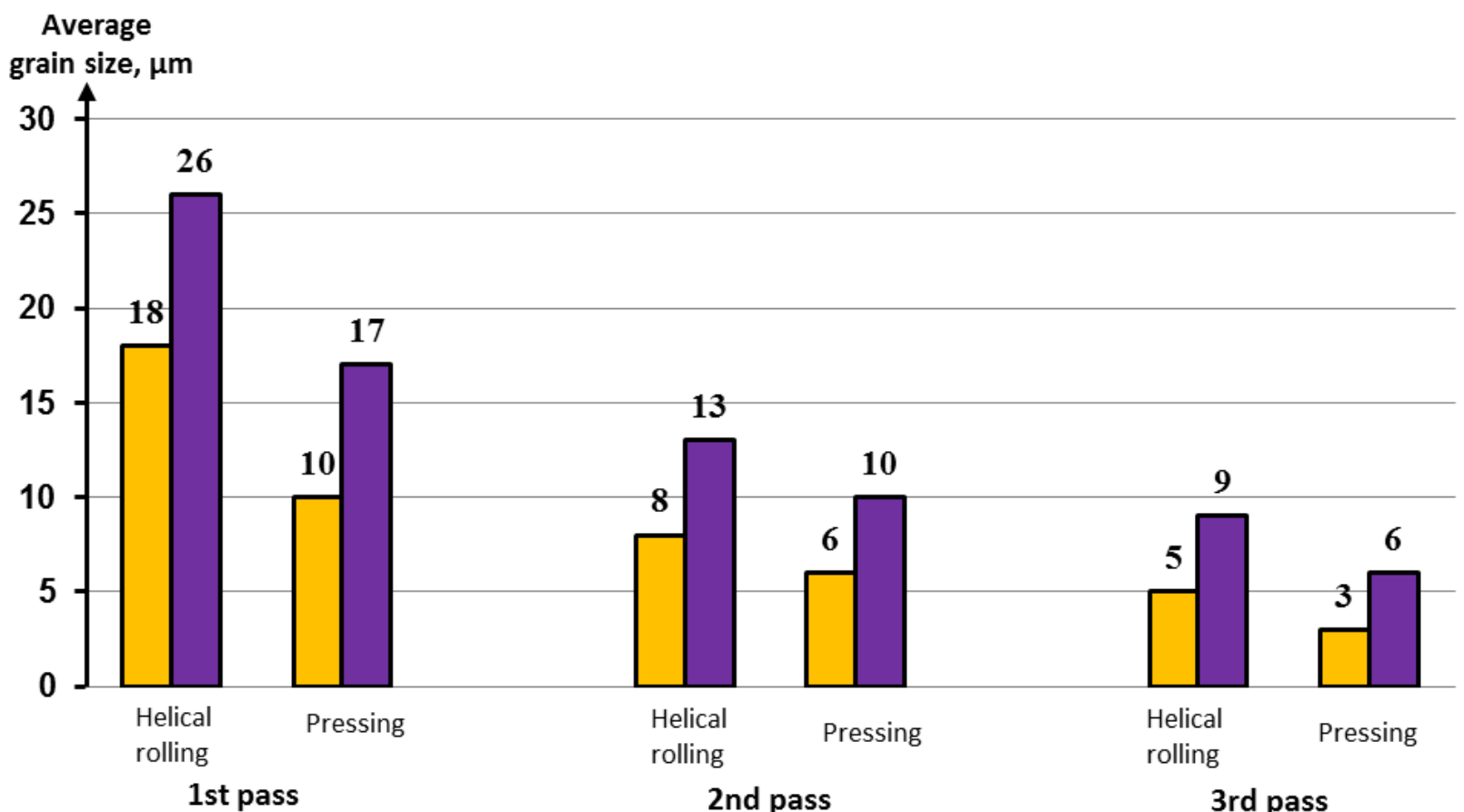

\section{口Surface area $\quad$ Central area}

Figure 8. Change of grain size during multipass deformation

\section{Conclusion}

A study of the microstructure evolution in the combined process "helical rolling-pressing", it was found that this combined method of deformation can significantly grind the original grain size. The variation of the main technological parameters showed that the influence of the heating temperature of the workpiece plays a significant role in the degree of grinding grain. While the speed of deformation, within the permissible installation designs, has no significant effect on the microstructure.

Due to the helical rolling the grain milling occurs mainly in the surface layers of the workpiece. The subsequent pressing in the matrix leads to a change in grain size over the entire cross section of the workpiece. But despite this, the difference values of the mean diameter of the grain between the central and surface area remains. To reduce the observed dispersion of values and the alignment of the grain size in the cross section it is necessary to expose the workpiece to several cycles of deformation. So, after the third pass, the difference of the average values of grain size between the central and surface area is only $3 \mu \mathrm{m}$, which is significantly lesser than that after the first passage $(7 \mu \mathrm{m})$. This allows to speak about quite uniform in this study on the crosssection of the workpiece.

It should be noted that the obtaining of such results by ECAP method requires 4-6 cycles of pressing, while the presented results were obtained after three passes, with time of each pass for rods with $250 \mathrm{~mm}$ length is $5-8$ seconds. Performance, in this case, (according to the claimed performance of mill-bases a combined installation) will be up to $100 \mathrm{~kg} / \mathrm{h}$ of high quality round steel bar without length restrictions with sub-ultra-finegrained structure. This is significantly higher than the main competing processes and provides an opportunity to talk about the greater efficiency of the proposed process. 


\section{Acknowledgement}

Work is performed under the state budget-funded theme "Innovative energy - saving technology to obtain subultra-fine-grained structural metals and alloys new combined process "helical rolling-pressing" with the program "Grant financing of scientific researches on 2015-2017" (Customer - the Ministry of education and science of the Republic of Kazakhstan).

\section{References}

1. H. Yada, N. Matsuzu, K. Nakajima, K. Watanabe and H. Tokita. Trans. ISIJ 23.100-109 (1983)
2. GOST 5639-82. Steel and alloys. Methods of detection and determination of grain size

3. R. Valiev, I. Alexandrov. Bulk nanostructured metal materials (Moscow, Akademkniga, 2007)

4. P. Berbon, N. Tsenev, R. Valiev, M. Furukawa, Z. Horita, M. Nemoto, T. Langdon. Metall Mater Trans A 29, 9, 2237-2243 (1998)

5. Z. Horita, D.J. Smith, M. Furukawa, M. Nemoto, R. Valiev, T. Langdon. J Mater Res 11, 8, 1880-1890 (1996)

6. R. Valiev, R. Islamgaliev, I. Alexandrov. Prog Mater Sci 45, 2, 103-189 (2000)

7. R. Valiev, T. Langdon. Prog Mater Sci 51, 881-981 (2006) 